Controversies in Therapeutics

\title{
Pain relief in active patients with cancer: analgesic drugs are the foundation of management
}

\author{
Mary Baines
}

The greatest fear of patients with cancer and of their families is unrelieved pain. Sadly, this fear has often been justified for in the past cancer pain has been poorly understood and inadequately treated. Fortunately, the situation is now improving and most patients with cancer in the developed world should be assured of good relief of pain with the appropriate use of analgesics, adjuvant drugs, radiotherapy, and nerve blocks.

\section{Prevalence of pain} varying from $30 \%$ to $45 \%$ in patients when cancer is diagnosed $^{1}$ and being up to $50 \%$ in children and adults receiving anticancer treatment, ${ }^{2}$ and $70 \%$ in those with advanced disease. ${ }^{3}$ The World Health Organisation estimates that every day 3.5 million people are suffering from cancer pain.

\section{Nature of cancer pain}

Pain has been described as a somatopsychic experience,' with its intensity depending both on the extent of tissue damage and on the patient's psychological state. In patients with cancer the pain will be exacerbated by associated physical symptoms such as anorexia or vomiting and by the inevitable fear of deterioration, separation, and death.

Pain is not only caused by an expanding tumour but may be due to the treatment, debility, or concurrent disease. In one study a third of the pains in patients with advanced cancer were non-malignant in origin and $80 \%$ of patients had more than one anatomically distinct pain. ${ }^{\circ}$

\section{Management of pain}

The very complexity of cancer pain with its multiple causes, exacerbating factors, and psychological issues, means that the simple approach of blocking the sensory nerves is unlikely to prove effective. A five pronged approach to controlling the pain is suggested (figure); in most cases more than one of these methods is required.

In practice after a careful diagnosis of the cause(s) of pain(s) most patients will require analgesic drugs. Paracetamol or codeine may be adequate for mild pain but more often oral morphine is needed. The dose must be given regularly (four hourly with paracetamol,
The prevalence of pain has been well studied,

codeine, and morphine solution; twelve hourly with slow release morphine). The dose should be individually determined, being the lowest compatible with controlling pain. Experience has shown that tolerance is a minor problem; addiction does not occur and the side effects of morphine such as nausea or constipation may be controlled.

Unfortunately, many patients and doctors still feel that if morphine is started early "it will lose its effect." The reverse is nearer the truth, and the really intractable pain, seen occasionally at the end of life, has often been preceded by months of inadequate control leading to depression, anger, and fear. Most radiotherapy departments and the home care sections of hospices have on their lists patients who have received morphine for several years. Many are active, perhaps at work, and pain remains controlled at a stable dose.

Adjuvant analgesic drugs are often helpful (figure), and their use may mean that analgesics are not required or can be given at a lower dose. They have specific indications-for example, non-steroidal antiinflammatory drugs for bone pain and corticosteroids for pain from raised intracranial pressure or nerve compression.

Palliative radiotherapy is most commonly used to control pain from a bony metastasis, relief of pain being achieved in $80 \%$ of patients. It is now recognised that a single treatment can be as effective as multiple fractions.

Patients and their families need ongoing emotional support. A few will benefit from professional counselling or relaxation techniques. All should receive regular appointments when there is the opportunity to discuss the implications of the illness, its future course, and its impact on the family.

With the wider use of these four methods of treating cancer pain, the demand for nerve blocks or neurosurgical techniques has fallen rapidly. Ventafridda found that in $197585 \%$ of his patients were treated with an interruption to pain pathways; in 1987 these methods were used in only $14 \%$. He attributes this fall to the introduction of the use of oral morphine and the beginning of the continuing care home service (V Ventafridda, European congress on palliative care, Milan, 1988).

The World Health Organisation also emphasises the crucial importance of treatment with drugs for cancer pain. It is pressing for the worldwide availability of oral

continued on page 38

\section{EDITORIAL COMMENT}

Anybody who has been in severe pain knows the importance of effective pain relief. Those who are in severe pain with an incurable disease but are none the less physically capable of reasonable activity know the importance of selectively inhibiting the pain without a wide range of intolerable unwanted effects from treatment. Although differing in the emphasis that they place on different methods of relieving pain, both Drs Baines and Lipton emphasise the importance of early intervention. Dr
Baines makes the important point that the lowest effective dose of narcotic drugs should be used and also emphasises that all types of analgesic may well be remarkably effective depending on the exact type of cancer concerned. The technique described by Dr Lipton has the attraction of power and selectivity in skilled hands but, as he says, skill is not so widespread. When, however, the more invasive procedures are available it is important that they should not be relegated to the method of last resort but used early when appropriate for the individual patient.-PETER RUBIN, professor of therapeutics, University Hospital, Nottingham NG7 2 UH 
Controversies in Therapeutics and other techniques. It is not comprehensive so refer to original papers for full details.

The injection of alcohol into the pituitary is in a different class. It is used for widespread, severe cancer pain, for pain in the head and neck, and when drug treatment and other techniques are inadequate. Forty per cent of patients obtain complete relief of pain for up to three months, $30 \%$ partial relief, and $30 \%$ no relief.

\section{Summary}

Analgesic drugs are the first line of pain relief in cancer, but they should not be the only treatment offered. If nerve blocks and other destructive procedures are to be used they should be used early with conviction and persistence. They might not be being used because there are not enough doctors who can use them properly.

1 Bonica JJ, ed. Cancer pain. New York: Raven, 1980:335-62.

2 Twycross RG, ed. Clinics in oncology. London: Saunders, 1984:5-15.

3 Foley KM. Pain syndromes in patients with cancer. In: Bonica JJ, Ventafridda $\mathrm{V}$, eds. Advances in pain research and therapy. Vol 2. New York: Raven, 1979:59-77.

4 Lipton S. Percutaneous cordotomy. In: Wall PD, Melzack R, eds. Textbook of pain. 1st ed. Edinburgh: Churchill Livingstone, 1984:632-8.

5 Thompson GE. Celiac plexus, intercostal, and minor peripheral blockade. In Cousins MJ, Bridenbaugh PO, eds. Neural blockade. Ist ed. Philadelphia: Lippincott, 1980:394-7.

6 Maher R, Mehta M. Spinal (intrathecal) and extradural analgesia. In: Lipton S, ed. Persistent pain. Vol 1. London: Academic, 1977:61-9.

7 Lloyd JW, Barnard JDW, Glynn CJ. Cryoanalgesia; a new approach to pain relief. Lancet 1976;ii:932-4.

8 Miles J. Pituitary destruction. In: Wall PD, Melzack R, eds. Textbook of pain. Ist ed. Edinburgh: Churchill Livingstone, 1984:656-65.

\section{Mary Baines}

continued from page 36 morphine because neurolytic and neurosurgical blocks are rarely available for they must be carried out by experienced specialists in a hospital or clinic. By contrast, the basic principles of managing pain with analgesics are remarkably easy to learn. After attending a week's workshop Takeda returned to Japan to test WHO's guidelines on the relief of cancer pain. ${ }^{+}$He found that over $80 \%$ of his patients became free of pain with drug treatment alone. ${ }^{8}$

There remains a small but important group, perhaps $5-10 \%$ of patients with cancer, who benefit from invasive procedures if they are available. These include

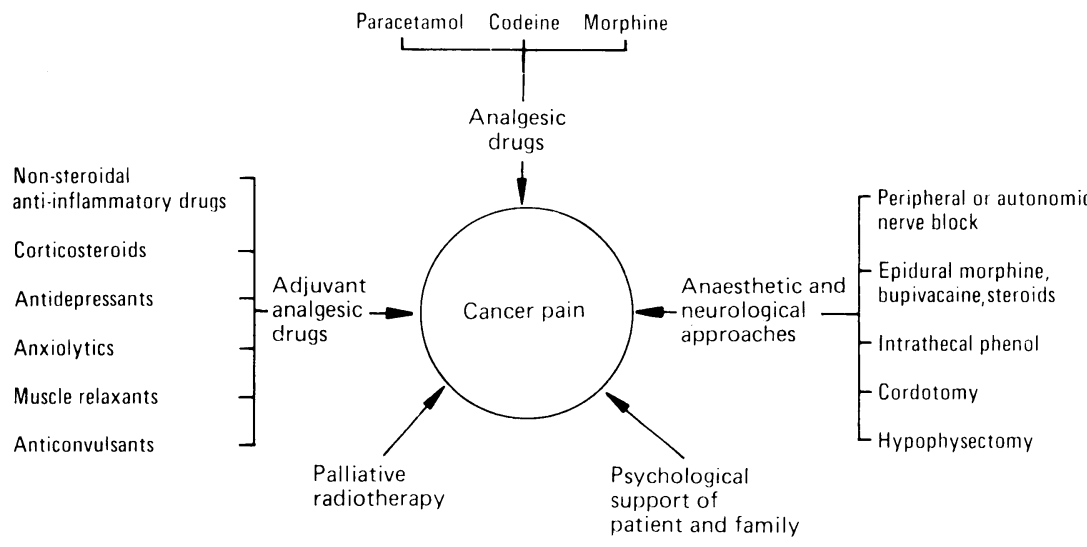

Treatment of cancer pain some with specific, localised pains, such as pancreatic or chest wall pain, which can be treated with appropriate nerve blocks. In addition, there is a small but as yet undefined group with intractable pain who will benefit from epidural or intrathecal drugs, or perhaps from a neurosurgical approach.

\section{Conclusion}

Over the past 20 years there has been a great upsurge of interest in the relief of cancer pain and reports indicate that the situation is improving. ${ }^{9}$ This change has been due to the much wider and more informed use of strong opioid drugs, but there still remains a small but important place for neural blockade.

Bonica JJ. Importance of the problem. In: Swerdlow M, Ventafridda V, eds. Cancer pain. Lancaster: MTP, 1987:3-7.

2 Foley KM. The management of pain of malignant origin. In: Tyler HR, Dawson DM, eds. Current neurology. Vol 2. Boston: Houghton Mifflin, 1979:279-302.

3 Bonica JJ. Treatment of cancer pain: current status and future needs. In: Field $\mathrm{HL}$, et al, eds. Advances in pain research and therapy. Vol 9. New York: Raven, 1985:589-616.

4 World Health Organisation. Cancer pain relief. Geneva: WHO, 1986.

5 Craig KD. Psychology of pain. Postgrad Med f 1984:60:835-40.

6 Twycross RG, Lack SA. Symptom control in far advanced cancer: pain relief. London: Pitman 1983:20-1.

Price P, Hoskin PJ, Easton D, Austin S, Palmer SG, Yarnold JR. Prospective randomised trial of single and multifraction radiotherapy schedules in the randomised trial of single and multifraction radiotherapy schedules in
treatment of painful bony metastases. Radiother Oncol 1986;6:247-55.

Takeda F. Results of field testing in Japan of the WHO draft interim guideline on relief of cancer pain. The Pain Clinic 1986;1:83-9.

9 Parkes CM, Parkes J. "Hospice" versus "hospital" care-re-evaluation after 10 vears as seen by surviving spouses. Postgrad Med $\mathcal{F}$ 1984;60:120-4

\section{WORDS}

JANUS WORDS Some words have two meanings each of which is the reverse, or nearly so, of the other. They have the same sound and may have the same spelling. There are also words that have reversed their meanings with the passage of time. In my private vocabulary I call this mixed bag Janus words, after the god in Roman mythology who was represented with two faces looking in opposite directions. No proprietary rights are claimed for my private vocabulary; please go ahead.

Here are some common examples. We climb the FELLS and go up the DOWNS. The German $a b$, pronounced "up," now naturalised in "abseiling," means "down." The expression "RAZED to the ground" perversely evokes in my mind's eye a group of Welsh miners who have just returned from the depths. CHUFFED, which until recently meant disgruntled, now means delighted. EGREGIOUS (L egregius; from ex, out + grege, from the flock), originally meant distinguished, excellent, and now means notorious. CLEAVE can mean "split, separate" or "adhere, unite." In the terminology of films a TRAILER precedes the film it advertises; in all other contexts it follows. A DIATRIBE once meant a discourse; it now means an invective harangue. In this connection, see Bernardo Ramazzini's De Morbis Artificum Diatriba (1700), the first book on occupational diseases.

ASPIRATE means "suck" in medical terminology and "blow" in phonetics. Thus we aspirate secretions from the bronchi, fluids from joints and serous cavities, and air from pneumothoraces. Patients may develop aspiration pneumonia owing to changes in the structure or function of the deglutition pathway, and most seriously perhaps from inhaled vomit. In phonetics, by contrast, an aspirate is the sound of the letter $\mathrm{H}$, and, more usually now, the $\mathrm{H}$ sound added to a vowel or consonant. This occurs, for example, in the word "pin," during that brief moment between the unvoiced $\mathrm{p}$ - and the voiced -in, (40-70 msec according to Gimson'). "Aspirate" derives from L aspiro (from ad + spiro), to breathe upon, to exhale. So the medical meaning branched off and reversed its direction. L spiro, to breathe, gave us "spirit" when breath (anima) was connected in mediaeval thinking with "soul." We now have, of course, respiration, expiration, and inspiration - this last also much used as a descendent of its ancient meaning. Transpire and perspire, by extension, are the emission of vapour from plants and animals respectively. Conspire ( $\mathrm{L}$ con, with) is to breathe together-obviously in a close huddle. Many will know the old tag, Dum spiro, spero (while I breathe, I hope)- often untrue, as every doctor knows. The surname Spiro, and its variant Shapiro, is Jewish and denotes an origin in the ancient German town of Speyer. In the United States Spiro is also the curtailed Greek surname Spiros, in turn from Spiridon. Spiro would be a fine name for a specialist in lung diseases, especially in the United Kingdom, where advertising is currently forbidden to doctors. B J FREEDMAN

1 Gimson AC. An introduction to the pronunciation of English. 3rd ed. London: Arnold, 1980:153. 